\title{
İkili Sözel Gösterim Tabanlı Bilişsel Haritanın Tedarik Zinciri Konfigürasyonunda Kullanımı
}

\author{
Mehtap DURSUN ${ }^{1^{*}}$, Nazlı GÖKER ${ }^{2}$ \\ ${ }^{1}$ Endüstri Mühendisliği Bölümü, Mühendislik ve Teknoloji Fakültesi, Galatasaray Üniversitesi, İstanbul, Türkiye \\ ${ }^{2}$ Endüstri Mühendisliği Bölümü, Mühendislik ve Teknoloji Fakültesi, Galatasaray Üniversitesi, İstanbul, Türkiye \\ ${ }^{* 1}$ mdursun@gsu.edu.tr, ${ }^{2}$ nagoker@gsu.edu.tr
}

(Geliş/Received: 27/08/2020;

Kabul/Accepted: 14/10/2020)

Öz: Günümüz rekabetçi pazar koşulları ve gelişmiş organizasyonel yapı firmaları tedarik zincirlerini daha verimli bir şekilde tasarlamaya yönlendirmektedir. Tedarik zinciri, artan küresel yetkinlik ve etkinlik kavramları nedeniyle daha önemli hale gelmektedir. Bu nedenle, firmalar için en iyi tedarik zinciri konfigürasyonunu (TZK) bulmak kritik durumdadır. Bu çalışmada riske karşı verilebilecek en uygun reaksiyonu belirlemek için tedarik zinciri yönetimi faktörleri incelenmektedir. İkili sözel gösterim modeli ve sözel hiyerarşiler, karar vericilerden farklı ölçekler kullanılarak elde edilen bilgilerin değerlendirme sürecinde kullanılmıştır. TZK'deki en önemli faktörleri belirlemek için bulanık bilişsel harita (BBH) metodolojisi uygulanmıştır. BBH metodolojisi, faktörler arasındaki sebep-sonuç ilişkilerinden, pozitif ve negatif ilişkilerden ve kesin veri eksikliğinden dolayı uygundur. Uygulama, Türkiye'nin en büyük üreticileri arasında yer alan bir otomobil fabrikasında gerçekleştirilmiş ve sonuçlar analiz edilmiştir.

Anahtar kelimeler: Bulanık bilişsel harita, bulanık karar verme, ikili sözel gösterim modeli, sözel hiyerarşiler, tedarik zinciri konfigürasyonu, tedarik zinciri yönetimi

\section{2-Tuple Fuzzy Linguistic Representation Model Based Cognitive Map for Supply Chain Configuration}

\begin{abstract}
Today's competitive market conditions and evolved organizational structure compel firms to design their supply chain more efficiently. Supply chain becomes more important because of growing global competence and effectiveness concepts. Therefore, managers endeavor to find best supply chain configuration (SCC) for their firms. This paper investigates the detailed evaluation of supply chain management factors by analyzing relationships and strength of them in order to determine the most appropriate reactions to the risks. 2-tuple linguistic representation model and linguistic hierarchies are used to cope with multi-granular linguistic information. Fuzzy cognitive map (FCM) methodology is employed to determine the most important factors in SCC. FCM methodology is appropriate due to cause-and-effect relationships among factors, positive as well as negative relationships, and the lack of crisp data. The application is conducted in an automobile factory, which is one of the largest manufacturers in Turkey, and the results are analyzed.
\end{abstract}

Key words: Fuzzy cognitive map, fuzzy decision making, linguistic hierarchies, supply chain configuration, supply chain management, 2-tuple linguistic representation model

\section{Giriş}

Günümüzün rekabetçi iş dünyası, tedarik zinciri yönetimini çok daha karmaşık ve dinamik hale getirmektedir. Bu rekabetçi ortamın yanı sıra, artan belirsizlikler de firmaları ciddi şekilde etkilemekte ve onları tedarik zinciri operasyonları boyunca sürdürülebilir yaklaşımlar geliştirmeye zorlamaktadır. Tedarik zinciri, hammaddelerden başlayarak nihai ürünlere kadar uzanır ve bunların organizasyonel ağ tarafından son tüketiciye teslim edilmesini kapsar ve aynı zamanda tersine lojistik içeren tüm süreçleri barındırır [1].

Tedarik zinciri yönetimi (TZY), planlama, uygulama ve kontrol etme gibi bazı temel aşamalara sahip tüm tedarik zinciri süreçlerinin bütünüdür [2]. Tedarik zinciri artan küresel yetkinlik ve etkinlik kavramı nedeniyle daha önemli hale gelmektedir. Bu nedenle, profesyoneller firmaları için en iyi tedarik zinciri konfigürasyonunu (TZK) bulmaya çalışmaktadır.

$\mathrm{Bu}$ çalışma, risklere en uygun reaksiyonları belirlemek için ilişkileri ve bunların gücünü analiz ederek tedarik zinciri yönetimi faktörlerinin ayrıntılı değerlendirmesini incelemektedir. Farklı ölçekler kullanılarak elde edilmiş olan sözel verileri değerlendirmeye katabilmek için ikili sözel gösterim modeli ve sözel hiyerarşiler kullanılmaktadır. Bulanık bilişsel haritalama (BBH) metodolojisi, TZK'deki en önemli faktörleri belirlemek için kullanılmaktadır. BBH metodolojisi, faktörler arasındaki sebep-sonuç ilişkilerinden, olumsuz ve olumlu

\footnotetext{
* Sorumlu yazar: mdursun@gsu.edu.tr. Yazarların ORCID Numarası: ${ }^{1}$ 0000-0002-7684-0319, ${ }^{2}$ 0000-0003-0820-6989
} 
ilişkilerden ve net veri eksikliğinden dolayı bu çalışma için uygundur. Ayrıca, belirli konsept düğümlerin artış veya azalışının diğer konsept düğümler üzerindeki önem derecesinin etkisini anlamak için üç senaryo analizi uygulanmıştır.

Önerilen yaklaşımın literatüre katkıları şu şekilde özetlenebilir. İlk olarak, çalışma risk faktörlerini dikkate alarak TZY ölçütlerini kapsamlı bir şekilde incelemektedir. Dahası, ikili sözel gösterim modeli ve sözel hiyerarşiler farklı ölçeklerde elde edilmiş verilerin ele alınmasını sağlamaktadır. Böylelikle, karar vericilerin değerlendirmelerinde, kişisel deneyim ve görüşlerinden kaynaklanan farklılıklar ve benzerlikler ortaya koyulmakta ve karar vericiler tarafindan farklı belirsizlik dereceleri kullanılarak verilen bilgiler karar sürecine dahil edilmektedir. Bununla birlikte, ikili sözel gösterim ve sözel hiyerarşiler, bulanık sözel yaklaşımların kullanılması ile ortaya çıkan veri kaybı sorununu en aza indirgemektedir. TZK değerlendirme faktör çiftleri arasındaki kesin sayılar kullanılarak ifade edilemeyen sebep sonuç ilişkileri, BBH kullanılarak değerlendirmeye katılmaktadır. Bu sayede TZK değerlendirme faktörlerinin önem dereceleri bulunmuş olup, bir faktörün önemindeki azalmanın diğer faktörlerin önemi üzerindeki etkisi, çeşitli senaryo analizleri yapılarak tanımlanmıştır. Senaryo analizleri, gelecekte karşılaşılması öngörülen problemlere proaktif çözüm önerisi geliştirilmesine olanak sağlamaktadır.

Çalışmanın ikinci bölümü TZK üzerine yapılmış yazın taramasını içermektedir. Üçüncü bölümde ikili sözel gösterim modelini ve sözel hiyerarşileri açıklanmaktadır. Dördüncü bölüm BBH metodolojisini anlatmaktadır. Beşinci bölümde, önerilen yaklaşım verilmektedir. Otomotiv sektöründe gerçekleştirilmiş vaka incelemesi altınc1 bölümde gösterilmektedir. Bölüm yedide tartı̧̧a ve senaryo analizlerine yer verilmiştir. Son olarak, bölüm sekiz, sonuçları ve gelecek araştırma yönelimlerini sunmaktadır.

\section{Yazın Taraması}

Son yıllarda, bilim adamları TZK için farklı karar verme yaklaşımları geliştirmeye odaklandılar. Beamon ve Fernandes [3] TZK için çok dönemli tamsayı programlama modelini önerdi. Huang ve diğerleri [4], bir dizi platform ürününün konfigürasyonunu ve bir üretici ile birden fazla tedarikçiden oluşan ilgili tedarik zincirinin eniyilemesini üç hamleli dinamik oyun teorisi yaklaşımı önererek sağladı. Akanle ve Zhang [5] TZK'yi müşteri talebi ile belirli bir süre boyunca başa çıkacak şekilde eniyilemek için bir metodoloji önerdi. Önerilen çok ajanlı sistem bir tedarik zincirinde bulunan kaynak seçeneklerinin yanı sıra operasyonel ortamlarda meydana gelen dinamik değişiklikleri modellemek için kullanıldı. Zhang ve Huang [6] platform ürünlerinin ve tedarik zincirlerinin eşzamanlı konfigürasyonu için oyun teorisine dayalı bir yaklaşım önerdi. Ashayeri ve diğerleri [7] tedarik zincirinde partner ve konfigürasyon seçimi için choquet integral tabanlı sezgisel bulanık karar verme yaklaşımı geliştirdi. Amin ve Zhang [8] sökme, yenileme ve bertaraf alanlarını içeren bir genel kapalı döngü tedarik zinciri ağı yapılandırdı. Li ve Womer [9] sipariş üzerine üretim temelli tedarik zincirlerinin konfigürasyonunu hem kaynak bulma hem de planlama kararları açısından eniyilemek için bir karar modeli geliştirdi. Amin ve Zhang [10] genel kapalı döngü tedarik zinciri ağını yapılandırmak için üç aşamalı bir model geliştirdi. İlk aşamada, değerlendirme sürecindeki nitel faktörleri göz önünde bulundurmak için yeni bir kalite fonksiyon yayılımı (QFD) modeli önerildi. İkinci aşamada, genel kapalı döngü tedarik zinciri ağını yapılandırmak için bir stokastik karışık tamsayılı doğrusal olmayan programlama modeli önerildi. Üçüncü aşamada, en iyi tedarikçileri seçmek için çok amaçlı bir karma tamsayılı doğrusal programlama modeli geliştirildi. Kumar ve Chatterjee [11] ürün hattı seçim kararını TZK'ye entegre etmek için sezgisel bir karar verme yaklaşımı geliştirdi. Mourtzis ve Doukas [12] tabu arama yöntemlerini kullanarak TZK probleminin modellemesini ve çözümünü gerçekleştirdi. Kuang ve diğerleri [13] en düşük toplam tedarik zinciri maliyetine sahip olan TZK'yi bulmak için bir eniyileme problemi formüle etti. Bu problemi çözmek için dinamik programlama tabanlı bir algoritma geliştirdiler. Kisomi ve diğerleri [14] TZK ve tedarikçi seçimini birlikte ele aldı ve bu problem için karma tamsayılı doğrusal programlama modeli önerdi. Arashpour ve diğerleri [15] prefabrike ürünlerin gelişmiş imalatında TZK parametrelerinin eniyilemesini gerçekleştirdi. Song ve diğerleri [16] tedarik zinciri ağı tasarımını etkileyen faktörleri içeren bir karar verme modeli önerdi. Srai ve diğerleri [17] kimya sektöründe TZK'yi analiz etmek için bir karar verme modeli sundu. $\mathrm{Bu}$ sayede, tedarik ağlarının ekonomik uygulanabilirliğini, çevresel olarak sürdürülebilirliğini ve sosyal açıdan kabul edilebilirliğini etkileyen ölçütleri inceledi. Son zamanlarda, Gaur ve diğerleri [18] yeni ve yeniden yapılandırılmış ürünlerin çok kaynaklı kapalı döngü TZK eniyilemesi için karma tamsayılı doğrusal olmayan bir programlama modeli geliştirdi. Dursun and Gumus [19] sezgisel bulanık bilişsel harita yöntemini kullanarak tedarik zinciri konfigürasyon kriterlerini değerlendirmiştir. Zhang ve diğerleri [20] maliyeti ve temin süresini en 
küçükleyen çok amaçlı TZK modeli geliştirmiştir. Li ve diğerleri [21] gıda TZK için karma tamsayılı doğrusal olmayan programlama modeli geliştirmiştir.

İncelenen çalı̧̧malar TZK yazınına katkıda bulunsa da bunların hiçbiri TZK faktörleri arasındaki nedensel ilişkileri dikkate almamakta ve farklı ölçekler kullanılarak elde edilmiş olan sözel verileri değerlendirmeye katamamaktadır. Halbuki, ölçütler arasında sebep-sonuç ilişkilerinin varlığı çok açıktır. Bu nedenle, TZK faktörleri arasındaki sebep-sonuç ilişkilerini hesaba katan bir analitik tekniğin kullanılması esastır. Dahası, verilerdeki belirsizliğin varlığı ele alınmalıdır. Bu nedenle, bu çalışmada, TZK faktörleri arasındaki sebep-sonuç ilişkilerini değerlendirmek için BBH metodolojisi kullanılmıştır. Bununla birlikte, karar vericilerden elde edilen verinin farklı ölçekler içermesi ikili sözel gösterim modelinin ve sözel hiyerarşilerin kullanımını gerektirmiştir. Son olarak, senaryo analizleri sayesinde belirli bir TZK değerlendirme ölçütünün önem derecesindeki azalış veya artı̧ın diğer ölçütler üzerindeki etkilerinin anlaşılması ve yorumlanması sağlanmıştır.

\section{3. İkili Sözel Gösterim ve Sözel Hiyerarşiler}

Bu çalışmada Herrera ve Martinez [22]'in önermiş olduğu ikili sözel gösterim yaklaşımı ve Cordon ve diğerleri [23] tarafından ortaya konmuş olan sözel hiyerarşiler kullanılmaktadır. İkili sözel gösterim yaklaşımı sözel değişkenler kullanılarak ifade edilmiş verinin $\left(s_{i}, \propto\right)$ şeklinde ikili gösterim ile ifade edilmesine olanak sağlamaktadır. Bu ifadede $s_{i}$, tanımlanmış temel sözel terim kümesini, $S_{T}$, sözel etiketini ve $\alpha$ sayısal değeri göstermektedir [24].

Tanım 1 [25]: $L=\left(\gamma_{0}, \gamma_{1}, \ldots, \gamma_{g}\right), S_{T}$ 'de belirlenmiş bir bulanık küme olmak üzere $L^{\prime}$ yi $[0, g]$ aralığında sayısal bir değere dönüştürecek olan fonksiyon

$\chi: F\left(S_{T}\right) \rightarrow[0, g]$,

$\chi\left(F\left(S_{T}\right)\right)=\chi\left(\left\{\left(s_{j}, \gamma_{j}\right), j=0,1, \ldots, g\right\}\right)=\frac{\sum_{0}^{g} j \gamma_{j}}{\sum_{0}^{g} \gamma_{j}}=\beta$

şeklinde tanımlanır. Tanımda $F\left(S_{T}\right) S_{T}$ 'de tanımlı bir bulanık kümedir.

Tanım 2 [22]: $S=\left(s_{0}, s_{1}, \ldots, s_{g}\right)$, bir sözel terim kümesi ve $\beta \in[0, g]$ sembolik birleştirme işleminin sonucunu gösteren değer olmak üzere, $\beta$ 'nın ikili sözel gösterimi

$\Delta:[0, g] \rightarrow S \times[-0.5,0.5)$,

$\Delta(\beta)=\left\{\begin{array}{cc}s_{i}, & i=\operatorname{round}(\beta) \\ \alpha=\beta-i, & \alpha \in[-0.5,0.5)\end{array}\right.$

olarak hesaplanır.

Önerme 1 [26]: $S=\left(s_{0}, s_{1}, \ldots, s_{g}\right)$,bir sözel terim kümesi ve $\left(s_{i}, \propto\right)$ ikili gösterim olsun. İkili gösterimden eşdeğeri sayısal $\beta \in[0, g] \subset \Re$. değerine dönmek için $\Delta^{-1}$ fonksiyonu kullanılmaktadır. Bu fonksiyon

$\Delta^{-1}: S \times[-0.5,0.5) \rightarrow[0, g]$,

$\Delta^{-1}\left(s_{i}, \alpha\right)=i+\alpha=\beta$

şeklinde ifade edilir.

Sözel hiyerarşiler sözel kuralların hiyerarşik sistemini tasarlamak için geliştirilmiştir. $l(t, n(t))$ sözel hiyerarşi seviyesini ifade etmek üzere $t$ hiyerarşinin seviyesini, $n(t)$ ise sözel değişken kümesinin belirsizlik derecesini belirtmektedir [23]. $t+1$ seviyesindeki sözel terimler kümesi $t$ seviyesinden Denklem (4) kullanılarak elde edilmektedir.

$L(t, n(t)) \rightarrow L(t+1,2 . n(t)-1)$

Hiyerarşide sözel terimler arasındaki dönüşüm Denklem (5) kullanılarak tanımlanmaktadır [23]:

$T F_{t^{\prime}}^{t}: l(t, n(t)) \rightarrow l\left(t^{\prime}, n\left(t^{\prime}\right)\right)$ 
$T F_{t^{\prime}}^{t}\left(s_{i}^{n(t)}, \alpha^{n(t)}\right)=\Delta\left(\frac{\Delta^{-1}\left(s_{i}^{n(t)}, \alpha^{n(t)}\right)\left(n\left(t^{\prime}\right)-1\right)}{n(t)-1}\right)$

\section{Bulanık Bilișsel Haritalama}

BBH, karar problemindeki faktörlerin etkilerini belirlemek için konseptler arasındaki sebep-sonuç ilişkilerini göz önünde bulunduran bir araçtır. Çok ölçütlü karar verme problemleri için pratik bir yöntemdir. Genel olarak, BBH'nin oluş̧urulması nedenselliğe dayanmaktadır. BBH yöntemi, bulanık mantık ve sinir ağlarını birleştiren bir sistem niteliğindedir [27].

$\mathrm{BBH}$, konsept düğümlerini, ağırlıklandırılmış okları, ve aynı zamanda geri bildirimleri içeren grafiksel gösterimdir. Ağırlıklandırılmış oklar, konseptler arasındaki ilişkileri nedensellik yönüyle temsil etmekte; nedensel ilişkinin var olup olmadığını, var ise pozitif veya negatif olduğunu göstermekte, ve konseptler arasındaki nedensel ilişkilerin üretildiği düğü̈mleri birbirine bağlamaktadır [28].

$C=\left(c_{1}, c_{2}, \ldots, c_{n}\right)$, genellikle bir durum, değişken, olay, eylem, amaç, değer veya sistemlerin diğer bir unsurunu temsil eden kavram kümelerinin temsilidir. Oklar, $C_{j}$ konseptinin $C_{i}$ konseptine ne kadar etki ettiğini göstermektedir. Sebep-sonuç ilişkilerinin önem değeri [-1,1] aralığında yer almakta ve "negatif olarak zayıf", "sıfir", "pozitif olarak çok güçlü" gibi sözel değişkenlerle gösterilmektedir. Şekil 1'de, bir BBH'nin grafiksel gösterimi verilmektedir.

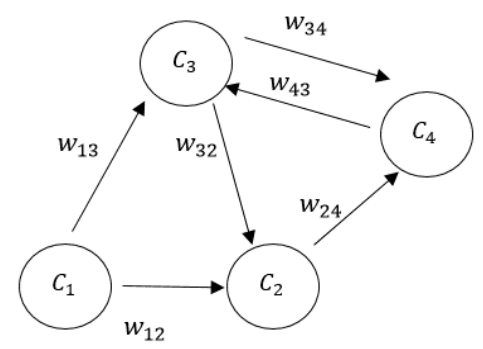

Şekil 1. BBH'nin grafiksel gösterimi

$w_{j i}$ 'nin işareti konseptler arasındaki sebep-sonuç ilişkilerinin yönünü göstermektedir. Eğer $w_{j i}>0$ ise, pozitif bir sebep-sonuç ilişkisi vardır, eğer $w_{j i}<0$ ise, $C_{j}$ ve $C_{i}$ kavramları arasında negatif bir sebep-sonuç ilişkisi vardır. Ayrıca $w_{j i}=0$ ise, ilgili kavramlar arasında nedensellik ilişkisi yoktur. Bu nedensel ilişkilerin gücünü belirlemek için ise $w_{j i}$ ağırlığına bir değer verilmelidir. Örneğin, Şekil l'de, $C_{2}$ konsepti $C_{3}$ 'te $w_{23}$ derecesinde bir artışa veya azalmaya neden olmaktadır. Her bir konseptin değeri aşağıda verilen iteratif denklem çalıştırılarak hesaplanır.

$A_{i}^{(k+1)}=f\left(A_{i}^{(k)}+\sum_{\substack{j \neq i \\ j=1}}^{N} A_{j}^{(k)} w_{j i}\right)$

$C_{i}$ konseptinin $k$. iterasyondaki değerini ifade etmektedir, $w_{i j}, c_{j}$ ve $c_{i}$ konseptleri arasındaki nedensel ilişkinin gücünü göstermektedir ve $f$ bir eşik fonksiyonudur. Tüm konseptlerin aktivasyon seviyeleri, BBH'de senkronize olarak güncellenmektedir. $A^{t}=\left[A_{1}^{t}, A_{2}^{t}, \ldots, A_{n}^{t}\right]$ vektörü BBH'nin $t$ adımındaki durumunu göstermektedir ve $n$, konseptlerin sayısıdır. Her konseptin bir iterasyon sonundaki değeri, aynı konseptin bir sonraki iterasyondaki değerine eşittir. BBH modellemesinin temel amacı, her bir konseptin önem derecesini veren son vektörü belirlemektir [28].

\section{5. Önerilen Karar Verme Yöntemi}

Geliştirilen yaklaşım aşağıda özetlenmekte ve Şekil 2'de gösterilmektedir. 


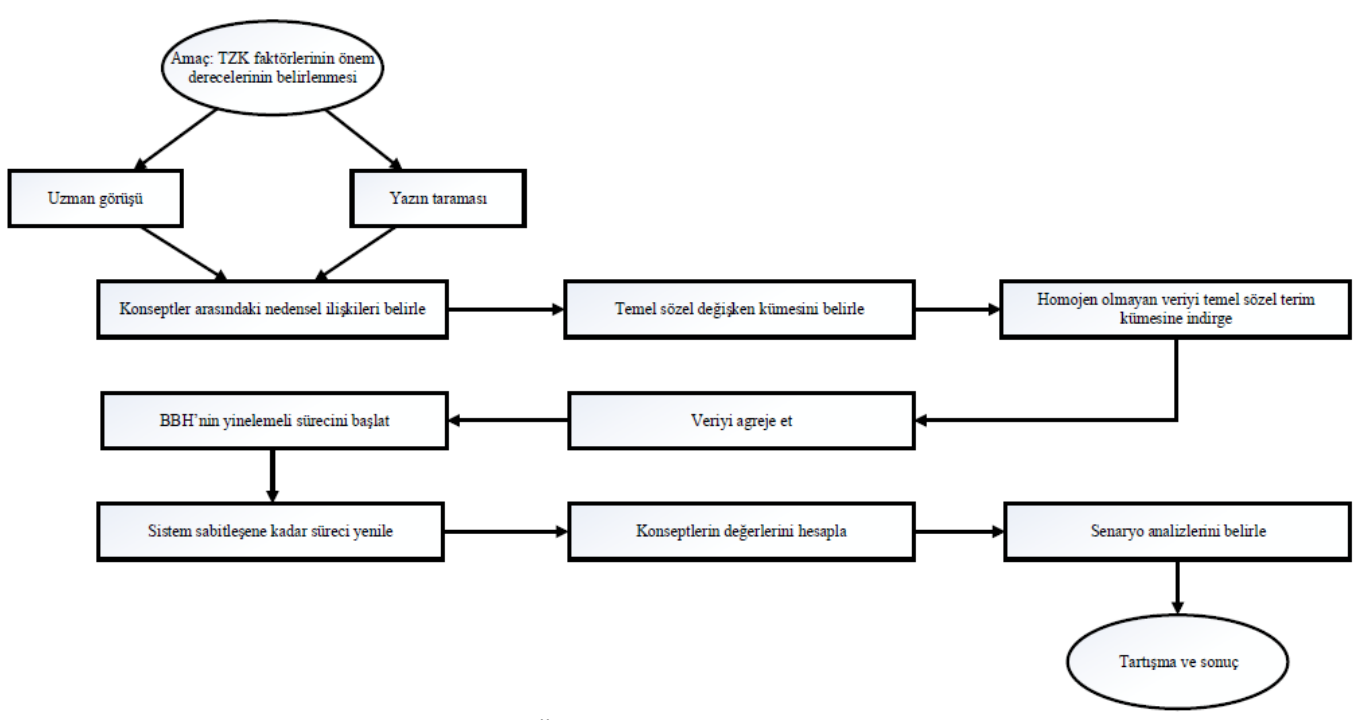

Şekil 2. Önerilen karar verme algoritması

Adım 1. Konseptler, uzman görüşleri ve yazın taraması sonucunda belirlenir.

Adım 2. Karar vericiler konseptler arasında var olan ilişkinin derecelerini Şekil 3 'te verilmiş olan $L H=$ $U_{t} l(1,3)$ sözel hiyerarşileri kullanarak ifade eder.

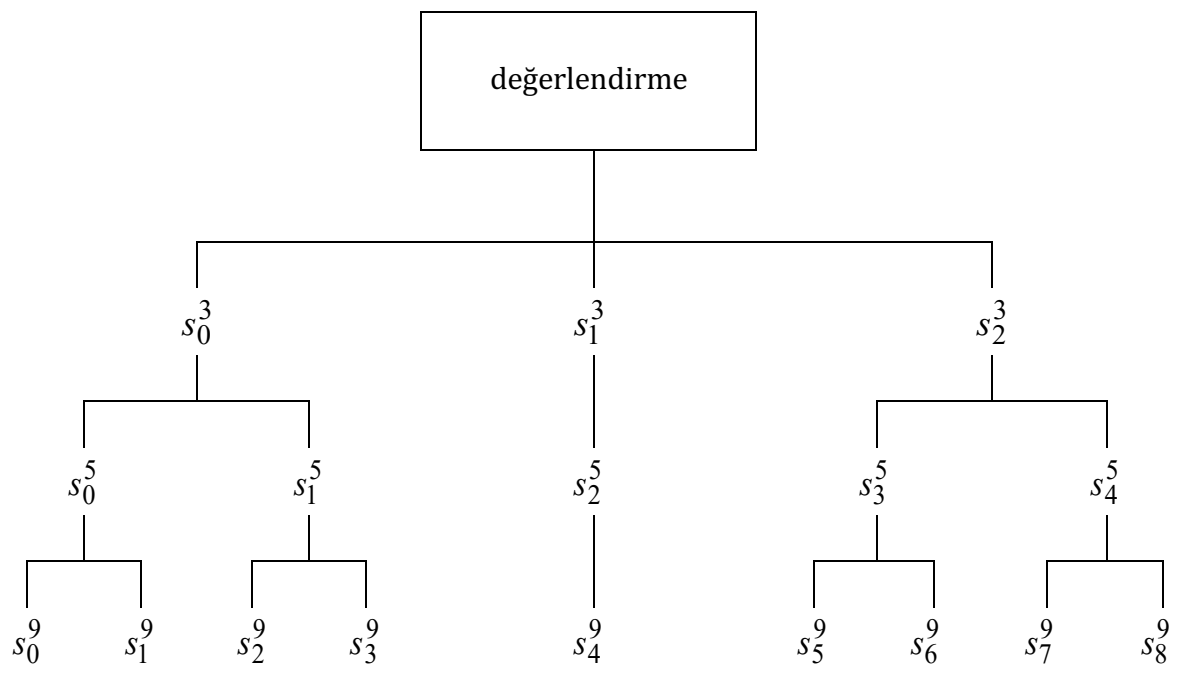

Şekil 3. Sözel hiyerarşi $L H=\bigcup_{t} l(1,3)[29]$.

Adım 3. Karar vericilerden farklı ölçeklerde elde edilmiş olan verileri birleştirmek için bir temel sözel değişken kümesi belirlenir ve homojen olmayan veriler Denklem (5) kullanılarak temel sözel terim kümesine indirgenir.

Adım 4. Aritmetik ortalama kullanılarak temel sözel terim kümesine indirgenmiş veriler birleştirilir.

Adım 5. BBH'ın yinelemeli süreci $A^{0}=[1,1, \ldots, 1]$ başlangıç vektörünü kullanarak başlatılır [28].

Adım 6. Başlangıç vektörü değeri Denklem (6) kullanılarak güncellenir. Sigmoid fonksiyonu konsept değerlerinin $[0,1]$ aralığında sınırlandırılması için uygun bir fonksiyondur.

Adım 7. Konsept değerleri Denklem (6) kullanılarak hesaplanır.

Adım 8. Senaryo analizleri gerçekleştirilir. 


\section{Vaka çalışması}

Vaka çalışması, Türkiye'nin en büyük otomobil üreticilerinden birinde gerçekleştirilmiştir. Tedarik zinciri konfigürasyonu oluşturmanın ilk adımı konseptlerin belirlenmesidir. Bu çalışmanın asıl amacı, karar vericilerin tedarik zincirini dinamik olarak kontrol etmelerine ve parametrelerin ilişkilerine göre eylemde bulunmalarına yardımcı olacak en iyi tedarik zinciri konfigürasyonunu belirlemektir.

Modelimiz Tablo 1'de gösterilmiş olan 13 konsepti içermektedir.

Tablo 1. TZK konseptleri

\begin{tabular}{ll}
\hline & Konsept \\
\hline$C_{1}$ & Tedarikçi entegrasyonu \\
$C_{2}$ & İç entegrasyon \\
$C_{3}$ & Müşteri entegrasyonu \\
$C_{4}$ & Teslim \\
$C_{5}$ & Kalite \\
$C_{6}$ & Esneklik \\
$C_{7}$ & Maliyet \\
$C_{8}$ & Yalın \\
$C_{9}$ & Çevik \\
$C_{10}$ & Talep ve tedarik belirsizliği \\
$C_{11}$ & Düşük duyarlılik performansı \\
$C_{12}$ & İşyerinde düşük kalite veya süreç verimi \\
$C_{13}$ & Uygun tedarikçi seçimi \\
\hline
\end{tabular}

Yazın araştırması ve uzmanların bilgisi ile belirlenmiş olan TZK modeli, tedarik zinciri yönetimi hakkında sağlam bir geçmişe ve derin bilgiye sahip üç uzman tarafından analiz edilmiştir. Uzmanlar bir konseptin diğeri üzerindeki etkisini belirtirler. Başlangıçta, her bir konsept çifti arasında nedensel bir ilişki olup olmadığını belirtirler. İlişki yoksa, ilgili konsept çiftini atlarlar, ancak nedensel bir bağlantı varsa, Şekil 3 'te verilen sözel hiyerarşileri kullanarak ilişkinin gücünü gösterirler. Uzmanların değerlendirmesi Tablo 2'de verilmişstir.

Tablo 2. Uzman görüşlerine göre faktörler arasındaki ilişkilerin gücü

\begin{tabular}{|c|c|c|c|c|c|c|c|c|c|c|c|c|c|}
\hline & $C_{1}$ & $C_{z}$ & $C_{3}$ & $c_{4}$ & $c_{5}$ & $C_{6}$ & $c_{c}$ & $C_{\mathrm{s}}$ & $c_{g}$ & $C_{10}$ & $C_{11}$ & $C_{12}$ & $C_{13}$ \\
\hline 1 & - & $\cdot$ & $\left(s_{1}^{5}, s_{0}^{3}, s_{2}^{9}\right)$ & $\left(s_{2}^{5}, s_{1}^{3}, s_{5}^{9}\right)$ & $\left(s_{4}^{5}, s_{2}^{3}, s_{8}^{9}\right)$ & $\left(s_{4}^{5}, s_{2}^{3}, s_{8}^{9}\right)$ & - & $\left(s_{3}^{5}, s_{1}^{3}, s_{6}^{9}\right)$ & $\left(s_{2}^{5}, s_{2}^{3}, s_{8}^{9}\right)$ & - & $\left(s_{4}^{5}, s_{2}^{3}, s_{7}^{9}\right)$ & 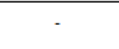 & $\left(s_{3}^{5}, s_{2}^{3}, s_{8}^{9}\right)$ \\
\hline$c_{2}$ & $\left(s_{1}^{5}, s_{0}^{3}, s_{2}^{9}\right)$ & - & $\left(s_{2}^{5}, s_{0}^{3}, s_{3}^{9}\right)$ & - & $\left(s_{1}^{5}, s_{0}^{3}, s_{3}^{9}\right)$ & - & - & $\left(s_{2}^{5}, s_{0}^{3}, s_{2}^{9}\right)$ & - & - & - & - & - \\
\hline 3 & $\left(s_{3}^{5}, s_{2}^{3}, s_{8}^{9}\right)$ & - & - & $\left(s_{3}^{5}, s_{2}^{3}, s_{6}^{9}\right)$ & - & - & $\left(s_{1}^{5}, s_{1}^{3}, s_{3}^{9}\right)$ & - & - & $\left(s_{3}^{5}, s_{2}^{3}, s_{8}^{9}\right)$ & - & - & - \\
\hline a & - & & - & . & - & - & - & - & 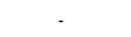 & - & . & . & - \\
\hline$F_{5}$ & - & - & $\left(s_{2}^{5}, s_{1}^{3}, s_{3}^{9}\right)$ & - & - & - & $\left(s_{4}^{5}, s_{2}^{3}, s_{8}^{9}\right)$ & - & - & - & $\left(s_{3}^{5}, s_{2}^{3}, s_{7}^{9}\right)$ & $\left(s_{4}^{5}, s_{2}^{3}, s_{8}^{9}\right)$ & $\left(s_{4}^{5}, s_{2}^{3}, s_{6}^{9}\right)$ \\
\hline 6 & . & & . & . & . & & - & $\left(s_{3}^{5}, s_{1}^{3}, s_{6}^{9}\right)$ & $\left(s_{4}^{5}, s_{2}^{3}, s_{7}^{9}\right)$ & & . & - & $\left(s_{3}^{5}, s_{2}^{3}, s_{8}^{9}\right)$ \\
\hline ; & - & - & - & - & $\left(s_{3}^{5}, s_{2}^{3}, s_{6}^{9}\right)$ & - & - & - & - & $\left(s_{3}^{5}, s_{2}^{3}, s_{7}^{9}\right)$ & - & - & - \\
\hline$c_{s}$ & - & - & - & - & $\left(s_{4}^{5}, s_{2}^{3}, s_{7}^{9}\right)$ & - & - & - & $\left(s_{3}^{5}, s_{2}^{3}, s_{7}^{9}\right)$ & - & - & $\left(s_{3}^{5}, s_{2}^{3}, s_{6}^{9}\right)$ & - \\
\hline$c_{g}$ & - & - & - & - & $\left(s_{4}^{5}, s_{2}^{3}, s_{7}^{9}\right)$ & $\left(s_{4}^{5}, s_{2}^{3}, s_{8}^{9}\right)$ & - & $\left(s_{3}^{5}, s_{2}^{3}, s_{8}^{9}\right)$ & - & - & $\left(s_{3}^{5}, s_{2}^{3}, s_{7}^{9}\right)$ & $\left(s_{4}^{5}, s_{2}^{3}, s_{7}^{9}\right)$ & $\left(s_{3}^{5}, s_{2}^{3}, s_{7}^{9}\right)$ \\
\hline$C_{10}$ & $\left(s_{4}^{5}, s_{2}^{3}, s_{7}^{9}\right)$ & - & - & - & - & - & $\left(s_{2}^{5}, s_{1}^{3}, s_{4}^{9}\right)$ & $\left(s_{3}^{5}, s_{2}^{3}, s_{7}^{9}\right)$ & - & - & $\left(s_{4}^{5}, s_{2}^{3}, s_{8}^{9}\right)$ & - & - \\
\hline$c_{11}$ & $\left(s_{3}^{5}, s_{1}^{3}, s_{5}^{9}\right)$ & $\left., s_{2}^{3}, s_{6}^{9}\right)$ & $\left(s_{3}^{5}, s_{2}^{3}, s_{7}^{9}\right)$ & - & - & $\left(s_{3}^{5}, s_{1}^{3}, s_{7}^{9}\right)$ & . & . & - & $\left(s_{2}^{5}, s_{0}^{3}, s_{3}^{9}\right)$ & . & - & - \\
\hline$c_{12}$ & - & - & . & - & - & - & - & - & - & - & - & . & $\left(s_{3}^{5}, s_{2}^{3}, s_{8}^{9}\right)$ \\
\hline 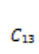 & - & - & . & $\left(s_{2}^{5}, s_{0}^{3}, s_{3}^{9}\right)$ & $\left(s_{3}^{5}, s_{2}^{3}, s_{8}^{9}\right)$ & $\left(s_{3}^{5}, s_{2}^{3}, s_{6}^{9}\right)$ & $\left(s_{4}^{5}, s_{2}^{3}, s_{7}^{9}\right)$ & $\left(s_{1}^{5}, s_{1}^{3}, s_{4}^{9}\right)$ & $\left(s_{3}^{5}, s_{2}^{3}, s_{7}^{9}\right)$ & - & 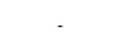 & $\left(s_{3}^{5}, s_{2}^{3}, s_{8}^{9}\right)$ & . \\
\hline
\end{tabular}

Farklı ölçeklerden elde edilmiş verileri birleştirmek için $l(2,5)$ temel sözel terim kümesi olarak kullanılmıştır. Elde edilen sonuçlar Tablo 3'te gösterilmektedir. 
Tablo 3. İlişkilerin birleştirilmiş gücü

\begin{tabular}{|c|c|c|c|c|c|c|c|c|c|c|c|c|c|}
\hline & $C_{1}$ & $C_{z}$ & $C_{3}$ & $C_{4}$ & $c_{5}$ & $C_{6}$ & $C_{7}$ & $C_{\mathrm{g}}$ & $C_{9}$ & $C_{10}$ & $C_{11}$ & $C_{12}$ & $C_{13}$ \\
\hline$c_{1}$ & - & - & $\left(s_{1}^{5},-0.33\right)$ & $\left(s_{2}^{5}, 0.17\right)$ & $\left(s_{4}^{5}, 0\right)$ & $\left(s_{4}^{5}, 0\right)$ & - & $\left(s_{3}^{5},-0.33\right)$ & $\left(s_{3}^{5}, 0.33\right)$ & - & $\left(s_{4}^{5},-0.17\right)$ & - & $(54,-0.33)$ \\
\hline$c_{2}$ & $\left(s_{1}^{5},-0.33\right)$ & - & $\left(s_{1}^{5}, 0.17\right)$ & - & $\left(s_{1}^{5},-0.17\right)$ & - & - & $\left(s^{5}, 0\right)$ & - & - & - & - & - \\
\hline$C_{3}$ & $\left(5_{4}^{5},-0.33\right)$ & - & - & $\left(s_{3}^{5}, 0.33\right)$ & - & - & $\left(s_{2}^{5},-0.5\right)$ & - & - & $(54,-0.33)$ & - & - & - \\
\hline$C_{4}$ & - & - & - & - & - & - & - & - & - & - & - & - & - \\
\hline$C_{5}$ & - & - & $\left(5_{2}^{5},-0.17\right)$ & - & - & - & $\left(s_{4}^{5}, 0\right)$ & - & - & - & $\left(5_{4}^{5},-0.5\right)$ & $\left(s_{4}^{5}, 0\right)$ & $\left(5_{4}^{5},-0.33\right)$ \\
\hline$C_{6}$ & - & - & - & - & - & - & - & $\left(s_{3}^{5},-0.33\right)$ & $\left(s^{5},-0.17\right)$ & - & - & - & $(54,-0.33)$ \\
\hline$C_{7}$ & - & - & - & - & $\left(s_{3}^{5}, 0.33\right)$ & - & - & - & - & $(5,5,-0.5)$ & - & - & - \\
\hline$C_{s}$ & - & - & - & - & $\left(s^{5},-0.17\right)$ & - & - & - & $\left(5_{4}^{5},-0.5\right)$ & - & - & $\left(s_{3}^{5}, 0.33\right)$ & - \\
\hline$C_{9}$ & - & - & - & - & $\left(s^{5},-0.17\right)$ & $\left(s^{5}, 0\right)$ & - & $\left(5_{4}^{5},-0.33\right)$ & - & - & $\left(5_{4}^{5},-0.5\right)$ & $\left(s_{4}^{5},-0.17\right)$ & $\left(5_{4}^{5},-0.5\right)$ \\
\hline$C_{10}$ & $\left(s^{5},-0.17\right)$ & - & - & - & - & - & $\left(s_{2}^{5}, 0\right)$ & $\left(5_{4}^{5},-0.5\right)$ & - & - & $\left(s^{5}, 0\right)$ & - & - \\
\hline$C_{11}$ & $\left(s_{3}^{5},-0.5\right)$ & $\left(s_{3}^{5}, 0.33\right)$ & $(5.5,-0.5)$ & - & - & $\left(s_{3}^{5},-0.17\right)$ & - & - & - & $\left(s_{1}^{5}, 0.17\right)$ & - & - & - \\
\hline$C_{12}$ & - & - & - & - & - & - & - & - & - & - & - & - & $(54,-0.33)$ \\
\hline$C_{13}$ & - & - & - & $\left(s_{1}^{5}, 0.17\right)$ & $\left(5_{4}^{5},-0.33\right)$ & $\left(s_{3}^{5}, 0.33\right)$ & $\left(5_{4}^{5},-0.17\right)$ & $\left(s_{2}^{5},-0.33\right)$ & $\left(5_{4}^{5},-0.5\right)$ & - & - & $\left(s_{4}^{5},-0.33\right)$ & - \\
\hline
\end{tabular}

Konsept değerlerini hesaplamak için Denklem (6)'nın iteratif süreci, $A^{o}=[1,1, \ldots, 1]$ başlangıç vektörü kullanılarak başlatılmıştır. 100 'den fazla iterasyondan sonra sistem dengeye ulaşmış ve TZK konsept değerleri Tablo 4'te gösterildiği gibi hesaplanmıştır.

Tablo 4. TZK konseptlerinin değerleri

\begin{tabular}{lc}
\hline & Konsept değerleri \\
\hline$C_{1}$ & 0.9488 \\
$C_{2}$ & 0.8122 \\
$C_{3}$ & 0.9064 \\
$C_{4}$ & 0.8948 \\
$C_{5}$ & 0.9914 \\
$C_{6}$ & 0.9766 \\
$C_{7}$ & 0.9590 \\
$C_{8}$ & 0.9794 \\
$C_{9}$ & 0.9767 \\
$C_{10}$ & 0.9233 \\
$C_{11}$ & 0.9786 \\
$C_{12}$ & 0.9802 \\
$C_{13}$ & 0.9893 \\
\hline
\end{tabular}

Tablo 4, "kalite", "uygun tedarikçi seçimi”" ve "işyerinde düşük kalite veya süreç verimi”nin en önemli üç risk faktörü olduğunu göstermektedir. Firmalar genellikle performanslarını finansla performans (yatırım kar oranı, pazar payı, brüt kar, vs.) ve operasyonel performans olmak üzere 2 kategoride ölçümlemektedir. "Kalite", "uygun tedarikçi seçimi" ve "işyerinde düşük kalite veya süreç verimi" faktörleri en önemli operasyonel performans göstergeleri arasındadır. Çalışmanın sonunda bu üç faktörün en önemli risk faktörleri olarak sıralanması uygulanan yöntemin sonuçlarının tutarlılığını ortaya koymaktadır.

\section{Tartışma ve Senaryo Analizleri}

Teknolojik gelişmeler, hızlı değişen pazar koşulları ve müşterilerin artan gereksinimleri, firmaları rekabet avantajlarını korumak için güçlüklerle başa çıkmaya zorlamaktadır. Firmalar, performanslarını genellikle işletme performansı (yatırım getirisi, pazar payı, satı̧ getirisi vb.) ve operasyonel performans (esneklik, maliyet, teslimat, kalite vb.) adı verilen iki kategoride ölçmektedir. Bunlar sistemin etkinliğini değerlendirmek için önemli 
çıktılardır; bununla birlikte operasyonel performans ölçütleri, işletme performans ölçütlerinin bir girdisi olarak önemli bir rol oynamaktadır. TZY, operasyonların stratejik bir bileşenidir, verimli konfigürasyon, firmanın birçok avantajının yanı sıra, potansiyel dezavantajlara da sebep olabilmektedir.

Esneklik ve çeviklik, artan beklentilere, farklılaştırılmış gereksinimler ve belirsizlikler ile başa çıkmak için iki anahtar terimdir. Bu kavramların önemini azalttığımızda, yalın konseptinin, düşük kalite veya süreç verimliliğinin, ve uygun tedarikçi seçiminin etkisi çarpıcı biçimde azalmaktadır. Bununla birlikte, kalite ve düşük duyarlılık performansı biraz azalmaktadır.

Daha düşük duyarlılık performansı ve işyerinde düşük kalite veya süreç verimi, operasyonel etkinlik sağlanarak azalabilen risk faktörleridir. Bu risk faktörlerinin önem değerlerinin sıfira eşit olduğu durumda, çevresel belirsizliklerin etkileri etkin bir şekilde değerlendirilmektedir. Kalite, yalın ve çevik kavramlar dışındaki tüm kavramlar olumsuz yönde değişirken, iç entegrasyon dramatik biçimde azalmaktadır.

En önemli TZE kavramı olan uygun tedarikçi seçiminin önem derecesi azalırsa, tüm kavramlar olumsuz yönde etkilenmektedir. Ancak, teslim ve esneklik kavramlarının önem dereceleri önemli ölçüde azalmaktadır. Bu değişim tüm risk faktörlerinin önemini azaltmaktadır, çünkü bu faktör tedarik zincirinin sürdürülebilirliği için hayati bir ölçüttür. Çevik ve yalın konsept değerlerinin önemi azalmaktadır. Esnekliğin çeviklikle benzer dinamikleri vardır ve esnekliğin öneminin azalması bizim için beklenen bir sonuçtur.

\section{Sonuç}

$\mathrm{Bu}$ çalışmada hem literatür taraması hem de uzman bilgisi kullanılarak TZK faktörleri belirlenmiştir. Belirlenen konseptler arasında nedensellik ilişkisi olup olmadığına uzmanlar tarafından karar verilmiş̧tir. Her bir konsept çifti arasında nedensellik varsa, uzmanlar ilişkinin gücünü belirlemişlerdir. Uzmanlar tarafından farklı ölçekler kullanılarak belirlenen veriler ikili sözel gösterim modeli ve sözel hiyerarşiler kullanılarak birleştirilmiştir. Daha sonra, BBH metodolojisi kullanılarak her bir konseptin önem derecesi hesaplanmıştır. Kullanılan FCMapper yazılımının sonucuna göre, kalite, uygun tedarikçi seçimi ve işyerinde düşük kalite veya süreç verimi en güçlü üç faktör olarak tespit edilmiştir. Son olarak, belirli konsept(ler)in gücünün azalmasının diğer konseptler üzerindeki etkisini anlamak için üç farklı senaryo analizi yapılmıştır. Önerilen yaklaşımın avantajları şu şekilde sıralanabilir.

- Bu çalışma, risk faktörlerini dikkate alarak temel TZK ölçütlerini kapsamlı bir şekilde ele almaktadır.

- Homojen olmayan verilerin karar verme sürecine veri kaybı olmaksızın dahil edilmesi ikili sözel gösterim modeli ve sözel hiyerarşiler kullanılarak sağlamaktadır.

- TZK değerlendirme faktörleri arasındaki nedensel ilişkileri belirlemek için BBH kullanılmaktadır.

- Bir faktörün önem derecesindeki azalmanın, diğer faktörlerin gücüne etkisi, senaryo analizi yapılarak belirlenmektedir.

Önerilen yaklaşım faktörler arasında var olabilecek negatif yönlü sebep sonuç ilişkilerini göz ardı etmektedir. Gelecekteki çalışmalarda negatif yönlü ilişkilerin de değerlendirmeye katılması ve buna uygun BBH eşik fonksiyonunun kullanılması planlanmaktadır. Ayrıca, sektörlere göre değişebilen farklı TZK faktörlerinin çalışmaya dahil edilmesi öngörülmektedir. Bunun yanı sıra veri alınan uzman sayısının artırılması da hedeflenmektedir.

\section{Teşekkür}

Bu çalışmanın değerlendirme ölçütleri Doç. Dr. Mehtap Dursun danışmanlığında Güray Gümüş tarafından yazılan tezden alınmıştır.

$\mathrm{Bu}$ çalışma Galatasaray Üniversitesi Bilimsel Araştırma Projesi (Proje No: FBA-2020-1024) tarafindan desteklenmektedir.

\section{Kaynaklar}

[1] Iansiti M, Levien R. Strategy as ecology. Harvard Business Review 2004; 82(3), 68-81.

[2] Park JH, Lee JK, Yoo JS. A framework for designing the balanced supply chain scorecard. European Journal of Information Systems 2005; 14, 335-346.

[3] Beamon BM, Fernandes C. Supply-chain network configuration for product recovery. Production Planning \& Control 2004; 15(3), 270-281.

[4] Huang GQ, Zhang XY, Lo VHY. Integrated configuration of platform products and supply chains for mass customization: A game theoretic approach. IEEE Transactions on Engineering Management 2007; 54(1), 156-171.

[5] Akanle OM, Zhang DZ. Agent-based model for optimising supply-chain configurations. International Journal of Production Economics 2008; 115(2), 444-460. 
[6] Zhang X, Huang GQ. Game-theoretic approach to simultaneous configuration of platform products and supply chains with one manufacturing firm and multiple cooperative suppliers. International Journal of Production Economics 2010; 124(1), 121-136.

[7] Ashayeri J, Tuzkaya G, Tuzkaya UR. Supply chain partners and configuration selection: an intuitionistic fuzzy choquet integral operatör based approach. Expert Systems with Applications 2012; 39(3), 3642-3649.

[8] Amin SH, Zhang G. An integrated model for closed-loop supply chain configuration and supplier selection: multiobjective approach. Expert Systems with Applications 2012; 39(8), 6782-6791.

[9] Li H, Womer K. Optimizing the supply chain configuration for make-to-order manufacturing. European Journal of Operational Research 2012; 221(1), 118-128.

[10] Amin SH, Zhang G. A three-stage model for closed-loop supply chain configuration under uncertainty. International Journal of Production Research 2013; 51(5), 1405-1425.

[11] Kumar S, Chatterjee AK. A heuristic-based approach to integrate the product line selection decision to the supply chain configuration. International Journal of Production Research 2013; 51(8), 2399-2413.

[12] Mourtzis D, Doukas M. On the configuration of supply chains for assemble-to-order products: case studies from the automotive and the CNC machine building sectors. Robotics and Computer-Integrated Manufacturing 2015; 36, $13-24$.

[13] Kuang H, Hu SJ, Ko J. Concurrent design of assembly plans and supply chain configurations using and/or graphs and dynamic programingJournal of Manufacturing Science \& Engineering-ASME 2016; 138(5), 051011.

[14] Kisomi MS, Solimanpur M, Doniavi A. An integrated supply chain configuration model and procurement management under uncertainty: A set-based robust optimization methodology. Applied Mathematical Modelling 2016; 40(17-18), 7928-7947.

[15] Arashpour M, Bai Y, Aranda-mena G, et al. Optimizing decisions in advanced manufacturing of prefabricated products: theorizing supply chain configurations in off-site construction. Auto Construct 2017; 84, 146-153.

[16] Song G, Sun L, Wang Y. A decision-making model to support the design of a strategic supply chain configuration. Journal of Manufacturing Technology Management 2018; 29(3), 515-532.

[17] Srai JS, Tsolakis N, Kumar M, et al. Circular supply chains and renewable chemical feedstocks: A network configuration analysis framework. Production Planning \& Control 2018; 29(6), 464-482.

[18] Gaur J, Amini M, Rao AK. The impact of supply chain disruption on the closed-loop supply chain configuration profit: a study of sourcing policies. International Journal of Production Research 2020; 58(17), 5380-5400.

[19] Dursun M, Gumus G. Intuitionistic fuzzy cognitive map approach for the evaluation of supply chain configuration criteria. Mathematical Methods in the Applied Sciences 2020; 43(13), 7788-7801.

[20] Zhang X, Zhan ZH, Zhang J. A fast efficient local search-based algorithm for multi-objective supply chain configuration problem. IEEE Access 2020; 8, 62924-62931.

[21] Li H, Li D, Jiang D. Optimising the configuration of food supply chains. International Journal of Production Research 2020; https://doi.org/10.1080/00207543.2020.1751337.

[22] Herrera F, Martínez L. A 2-tuple fuzzy linguistic representation model for computing with words. IEEE Transactions on Fuzzy Systems 2000; 8(6), 746-752.

[23] Cordon O, Herrera F, Zwir I. Linguistic modeling by hierarchical systems of linguistic rules. IEEE Transactions on Fuzzy Systems 2002; 10(1), 2-20.

[24] Dursun M. Atık su yönetimi için bütünleşik bulanık çok ölçütlü karar verme yöntemi. Fırat Üniversitesi Mühendislik Bilimleri Dergisi 2018; 30(1), 209-217.

[25] Herrera F, Martínez L. An approach for combining linguistic and numerical information based on 2-tuple fuzzy representation model in decision-making. International Journal of Uncertainty. Fuzziness and Knowledge-Based Systems $2000 ; 8(5), 539-562$.

[26] Herrera-Viedma E, Herrera F, Martínez L, Herrera JC, López AG. Incorporating filtering techniques in a fuzzy linguistic multi-agent model for information gathering on the web. Fuzzy Sets and Systems 2004; 148(1), 61-83.

[27] Kosko B. Fuzzy cognitive maps. International Journal of Man-Machine Studies 1986; 24, 65-75.

[28] Büyükavcu A, Albayrak YE, Göker N. A fuzzy information-based approach for breast cancer risk factors assessment. Applied Soft Computing 2016; 38, 437-452.

[29] Huynh VN, Nakamori Y. A satisfactory-oriented approach to multiexpert decision-making with linguistic assessments. IEEE Transactions on Systems Man and Cybernetics Part B-Cybernetics 2005; 35(2), 184-196. 